International Research Journal of Management, IT \& Social Sciences
Available online at https://sloap.org/journals/index.php/irjmis/
Vol. 8 No. 3, May 2021, pages: 236-245
ISSN: 2395-7492
https://doi.org/10.21744/irjmis.v8n3.1471

\title{
Macro and Microeconomic Analysis of the Impact of the COVID-19 Pandemic in Chile and the Projections of the Central Banks
}

Rodrigo Ignacio Barra Novoa ${ }^{a}$

Article history:

Submitted: 9 February 2021

Revised: 27 March 2021

Accepted: 18 April 2021

\section{Keywords:}

central bank;

COVID-19;

economic growth;

macroeconomics;

microeconomics;

\section{Corresponding author:}

Barra Novoa, R. I.

Researcher and PhD student in Law and Economics Sciences at Camilo José Cela University - Spain. Award Level 8 in Strategic Management and Leadership by CMI, United Kingdom. Social economist, University of Tarapacá, Arica - Chile.

Email address: rodrigo.barra@centrossercotec.cl

\begin{abstract}
This article offers a first approximation of the impacts of the COVID-19 pandemic on the Chilean macro and microeconomic environment, using representative data from the latest formal surveys in the country. Here, the number of active firms plummeted in part due to the social crisis that began on October 18, 2019, and losses were felt in most industries due to the pandemic crisis that continues to generate job losses and low business profitability. These first results have implications for central bank policies and can predict medium and medium-term projections, especially for the country's economic and social growth.
\end{abstract}

International research journal of management, IT and social sciences (C) 2021. This is an open access article under the CC BY-NC-ND license (https://creativecommons.org/licenses/by-nc-nd/4.0/).

${ }^{a}$ Researcher and PhD student in Law and Economics Sciences at Camilo José Cela University - Spain | Award Level 8 in Strategic Management and Leadership by CMI, United Kingdom. 


\section{Introduction}

High inflation rates, deep recessions, currency devaluations and historically low interest rates: all of these have been frequent phenomena in the United States, Europe, Latin America and Chile and could reappear permanently if monetary and fiscal policies are not properly managed. Macroeconomic stability is never fully assured in any economy, as was dramatically demonstrated in the United States and in some European economies with the outbreak of the financial crisis that led to the great recession of 2008-2009 and, even less so, with the current COVID-19 pandemic, in which, despite all efforts, macroeconomic stability is still not sufficiently entrenched to enjoy the institutional and political support it has in more developed countries.

In this context, the management of monetary and fiscal policy instruments has undergone important changes for more than five decades in Europe and since the 1990s in Latin America and especially in Chile. Historical observation shows that monetary policies have become more effective and transparent, but they are not infallible. Since credibility is not achieved overnight according to data obtained from the Inter-American Development Bank (2015). Some institutional arrangements, such as the independence of the Central Bank, can help consolidate it. Therefore, the effectiveness of monetary policy also depends on the activism of the fiscal accounts and the financial sector.

In this context, a recent study by Robert Fairlie (2020) examines the impact of COVID-19 on small and mediumsized business owners, on the basis that the widespread closure of stores and businesses across the USA and throughout the global economy due to the coronavirus is unprecedented. The article establishes that factories and small businesses have closed due to health policies or changes in the structure of domestic and international demand. Although the effects of the coronavirus on the world economy were rapidly manifested in the stock market, the housing market, and the unemployment rate, according to Fairlie (2020), the impacts on SMEs are not well known due to the lack of up-todate enterprise-level data published by different governments. Contributions made in this document are key to estimating the initial effects on the owners of small businesses based on the macro and micro data of the Central Bank, INE and other financial and university entities.

In this context, most of the industries or sectors in Chile that suffered large declines are commerce, restaurants, hotels, arts and cultural services, and transport companies. Simulations and statistics suggest that the largest negative concentrations are found among entrepreneurs and small businesses.

\section{Literature Review}

The COVID-19 pandemic crisis that started in Wuhan, at the end of 2019 has spread internationally to more than 180 countries. This outbreak has been considered a pandemic by the World Health Organization (WHO, 2019) as it shows an increasing person-to-person infection according to Qiu, Rutherford, Mao \& Chu (2017). That has caused more than 900,000 deaths in recent months. Based on data reviewed by Liu, Gayle, Smith et al. (2020), COVID-19 recorded the highest infection and death rates compared to other coronavirus outbreaks. In proportion to population affected by the coronavirus, the cholera epidemic during the 19th century was one of the biggest diseases that Europe, various areas of America and Asia had, behind the Black Death. More than 10 million people died in the 1800s, becoming one of the most extensive and deadly diseases of the 19th century (Snow, 1958; Tang \& Peng, 2017).

Because of this, travel restrictions, social distancing and quarantines have been implemented in several countries, with varying duration. In many economies, quarantine orders to prevent the spread of the coronavirus have caused not only a psychological impact (Ghani, 2020; Dutta, 2002), but have impacted commercial activities, such as business closures and disruption of commodity supply chains (Fabeil et al., 2020).

Before analyzing the impact and strategies to offset the impact, it is essential to know what the definition of crisis is. Booth (1993) defines "crisis as a situation faced by an individual or an organization that cannot be dealt with through the use of normal routine processes". According the author, there are three types of crisis: gradual threat, periodic threat and sudden threat. The pandemic crisis can be visibly considered as a "surprise threat", since the crisis occurred suddenly and affects not only certain industries, but also regional economies.

The risks of complexity and uncertainty published in 1921 by Frank Knight, exposes a quite pertinent theory to the current scenarios of "risk" and "uncertainty" where the latter contemplates a series of random variables with unknown probabilities, where the role of the business sector is to ensure the income of the productive factors supporting the risk of the economic activity of the company. Given that risk is the measure of the uncertainty of the economic system, the effect of the pandemic outbreak on the international society and economy can be enormous and it is essential that recovery with all the technical and economic risks involved in the health crisis is essential to subsist in a new normal way of life.

Barra Novoa, R. (2021). Macro and microeconomic analysis of the impact of the COVID-19 pandemic in Chile and the projections of the central bank's. International Research Journal of Management, IT and Social Sciences, 8(3), 236-245. https://doi.org/10.21744/irjmis.v8n3.1471 
Countercyclical or countercyclical policy of the central bank

In an eventual countercyclical or countercyclical policy, fiscal or monetary policy can be oriented to attenuate the intensity of the economic cycle, contributing to the stability of production and employment. For example, the monetary policy of the Central Bank of Chile has a countercyclical orientation, subject to the preservation of price stability. Also, the literature considers that several economists do not believe that the central bank can exercise direct control over the quantity of money. However, they all accept that the central bank is the monopoly issuer of its own liabilities, which are virtually the entire monetary base, and that it necessarily controls the supply function of the assets in the monetary base.

Milton Friedman and other monetarist economists argued that the central bank can and should be concerned with the quantity of assets in the base. Moreover, he postulated that an increase in the quantity of the base had a roughly proportional positive effect - via the "base multiplier" - on the quantity of money. On the other hand, most monetary economists today believe that, in practice, central banks price central bank credit to influence a spectrum of interest rates, and that such operations have a less predictable influence on the quantity of money.

\section{Materials and Methods}

Data analysis

\section{Unemployment rate}

According to information obtained from the National Employment Survey (ENE), prepared by the National Statistics Institute (INE), in the June-August 2020 quarter, the unemployment rate reached 12.9\%, growing 5.3 percentage points in twelve months, as a result of reductions of $14.5 \%$ in the workforce and $19.4 \%$ in the employed. On the other hand, the number of unemployed increased by $46.0 \%$. In addition, the descriptive statistics by gender, for the third successive period in the series, the unemployment rate for men $(13.5 \%)$ is higher than that of women $(12.1 \%)$.

The seasonally adjusted unemployment rate stood at $12.5 \%$, unchanged from the previous quarter, as a result of the growth of the labor force $(1.4 \%)$, the unemployed $(1.3 \%)$ and the employed $(1.4 \%)$. The latter did not show quarterly increases since the November-January 2019 period. The employed presented a drop of $19.4 \%$, influenced by both men $(-17.4 \%)$ and women $(-22.2 \%)$. On the other hand, due to the implementation of the Employment Protection Law, the absent employed, which represent $17.3 \%$ of the total employed, grew by $120.1 \%$, equivalent to 680,382 people.

The decrease in the number of employed persons was influenced by the commerce sector $(-22.0 \%)$, construction ($34.9 \%)$, agriculture and fishing $(-34.3 \%)$ and accommodation and food services $(-45.2 \%)$, while, by occupational category, the main decreases were observed in self-employed workers $(-32.1 \%)$ and in formal employees $(-11.0 \%)$. The informal employment rate reached $22.6 \%$, with a decrease of $5.0 \mathrm{pp}$. In one year. Meanwhile, in men and women the rate registered $21.8 \%$ and $23.7 \%$ respectively, with variations of $-4.7 \mathrm{pp}$. and $-5.3 \mathrm{pp}$. On an annual basis, the volume of work, measured by the total effective hours worked by the employed, decreased by $30.8 \%$. Unequally, the average number of hours worked decreased by $14.2 \%$ to 32.7 hours.

The combined rate of unemployment and potential labor force reached $29.0 \%$, with an increase of $14.6 \mathrm{pp}$. In the period. In men it was $26.8 \%$ and in women $32.0 \%$. The gender gap was $5.2 \mathrm{pp}$. Finally, it is important to mention that the number of people who have left their jobs since March 2020, 65.4\% felt some reason that is directly linked to the COVID-19 pandemic (Central Bank of Chile, 2020). 


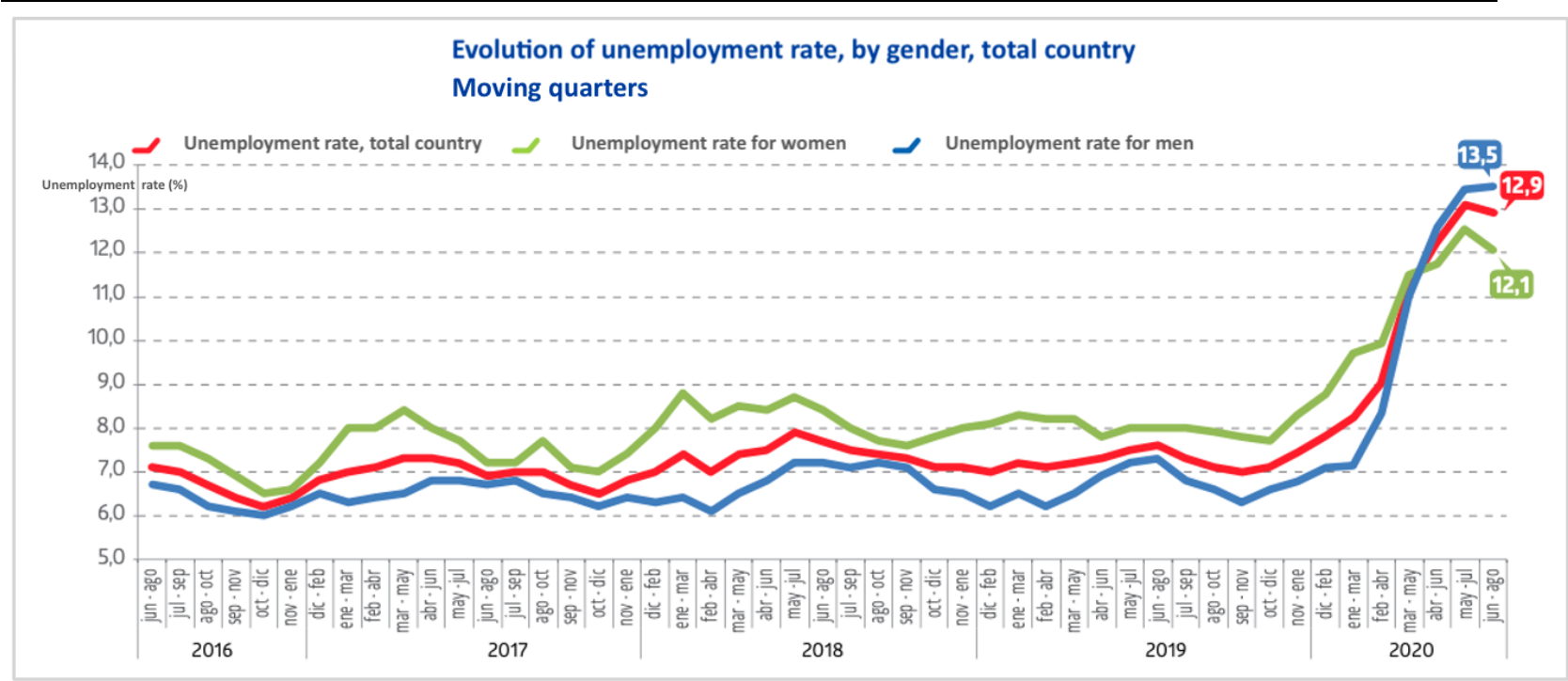

Source: Elaboration based on National Employment Newsletter, Mobile Quarter June - August 2020, INE.

Figure 1. Unemployment rate, by gender, total country

\section{Results and Discussions}

\section{Working Market}

In the "Business Perceptions Report for the month of August 2020 of the Central Bank of Chile" it is estimated that a significant fraction of those interviewed, especially from the most affected areas, state that they have accepted the Employment Protection Law and even have used this measure for longer than expected. Despite the foregoing, some mention having made layoffs in recent weeks, which in certain cases correspond to workers who were covered by said Law (Central Bank, 2020).

A part of those consulted indicates that the terminations could continue in the coming months. In the least affected sectors or in which teleworking is more feasible, no significant staffing adjustments are reported. In the opinion of those interviewed, the recovery of employment in the most damaged sectors will be slower than that of activity. Several indicate that the need to work with a more efficient structure will extend, at least as long as the social distancing measures continue. Even so, the economic literature establishes that when coming out of a recession, the company grows faster than the occupation. As the economy revitalizes, imports of capital goods grow and the capital labor ratio increases, improving productivity, but employment does not grow at the same rate.

In some areas, such as commerce and hotels, they indicate that they will not be able to function at full capacity for a long time. The exception is construction, where a rebound in employment is expected more in sync with activity, as the quarantines are lifted. However, several affirm that the sustainability of this recovery will depend on the appearance of new institutional projects and new regulatory and economic frameworks, which until now is uncertain (Central Bank, 2020).

Within this broad conception of the density of unemployment in the labor market, the existence of an articulated institutional framework, with joint economic recurrence projects and networking, acquires a significant role in increasing the opportunities that companies have (Costamagna, 2011), to face the difficulties of COVID-19, gradually improving their adaptation capacities to solve their problems, carry out innovations and define strategies in the face of the great challenges of the labor market and current economic dynamics. The intention of staffing recovery versus recovery of company sales is charted below.

Barra Novoa, R. (2021). Macro and microeconomic analysis of the impact of the COVID-19 pandemic in Chile and the projections of the central bank's. International Research Journal of Management, IT and Social Sciences, 8(3), 


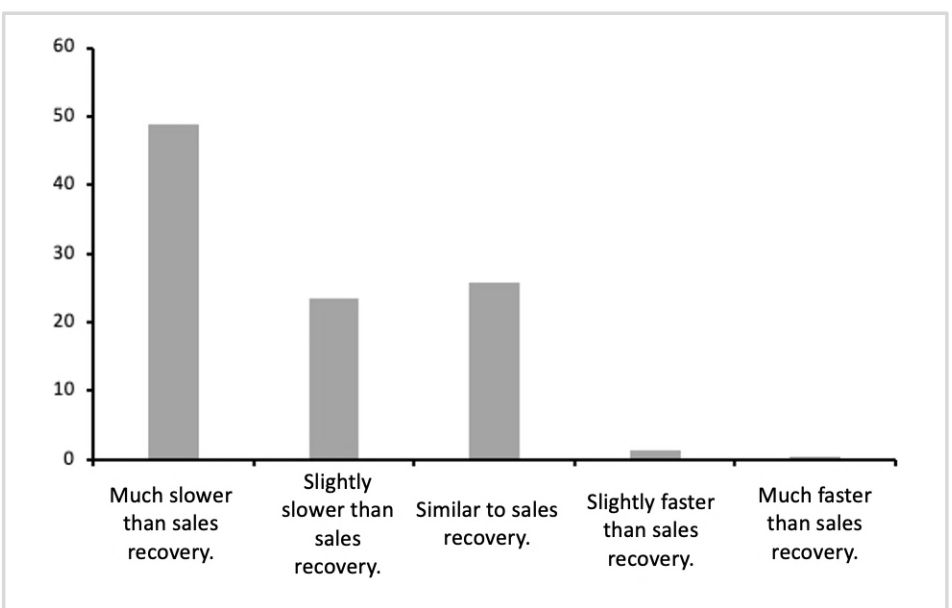

Source: Elaboration based on Central Bank of Chile, 2020.

Figure 2. Recovery of sales v/s recovery of staffing

\section{Inflation Indicators}

According to INE statistics, the monthly variation of $0.1 \%$ in the CPI (2.4\% per year) was in line with expectations and market expectations ( $0.1 \%$ according to EEE and according to Bloomberg). The SAE CPI, for its part, showed a monthly variation of $0.1 \%$ ( $1.8 \%$ annually), which is 0.1 percentage points higher than the variation in July. Although inflation still remains around the lower range of the Central Bank's target range, the slight rise in the SAE CPI is explained by the effects of the gradual reactivation that began at the end of July and the higher consumption derived from the stimulus measures (Grünwald \& García, 2020; Meluzín \& Zinecker, 2014).

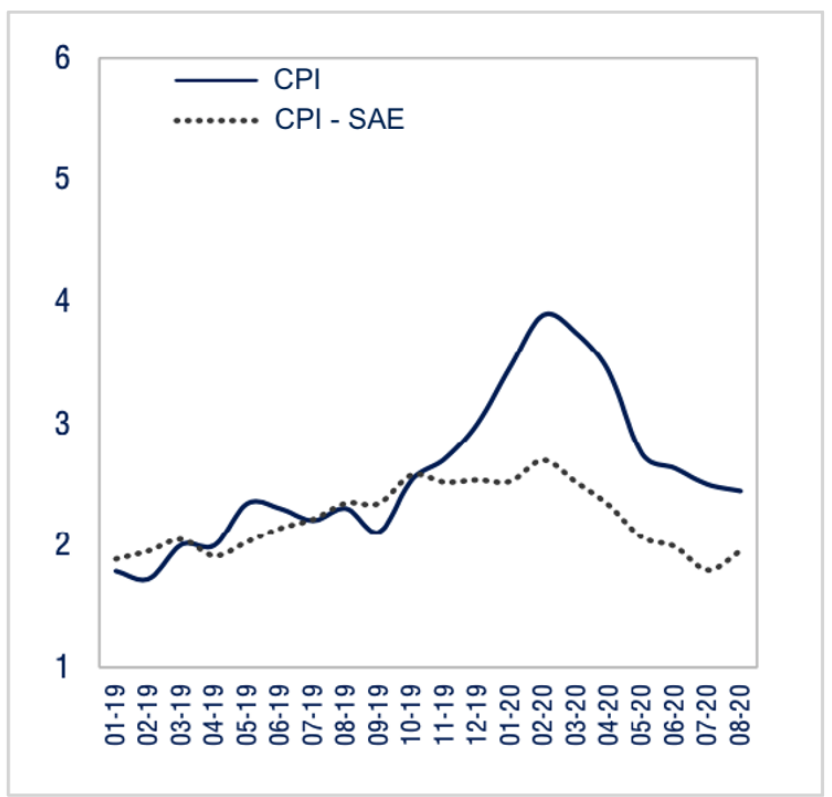

Source: Elaboration based on INE, 2020.

Figure 3. Inflation (\%)

The low levels of consumption caused by restrictions on mobility began to be reversed during the month of August, explained by the lifting of quarantines in communes of the Metropolitan Region and the implementation of consumer incentives such as the withdrawal of pension funds. This has been reflected in the positive incidence of divisions that showed setbacks during the pandemic, such as clothing and footwear. In this sense, the extraordinary withdrawal of 
up to $10 \%$ of the individually funded funds, although with little empirical evidence, had a heterogeneous impact on each of the contributors and their use based on age, sex, income and degree of income. Formality of his future employment, it was clearly used for the payment of debts, purchase of food and purchases of some durable goods.

At the same time, the price imputation rate (See Graph 4) decreased again, although it still remains above prepandemic levels. In this sense, the activities most affected by the imputation (and whose price variations are biased to zero) are those that still face operating restrictions, among them "Recreation and Culture" and "Restaurants and Hotels" (Grünwald \& García, 2020; Zore et al., 2016).

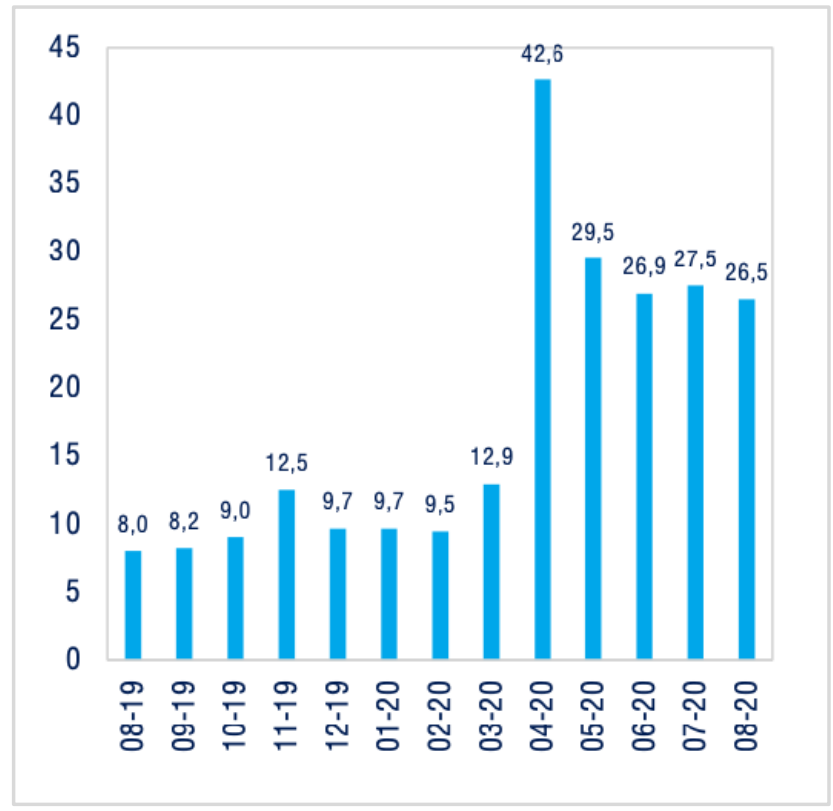

Source: INE, 2020.

Figure 4. Price imputation rate $(\%)$

\section{Current Macroeconomic Scenario}

According to the estimates of the Department of Banchile Inversiones Studies, for 2020 the growth estimates are maintained, however, the better economic expectations may push the unemployment rate up, because these would encourage the return of the inactive to the labor market. Therefore, for December of this year an unemployment rate of $15 \%$ (vs. $11.5 \%$ previously estimated) is estimated, while for December 2021 it is expected to be $10.6 \%$ (vs. $8.5 \%$ above) Notwithstanding the foregoing, if there is a re-outbreak of the pandemic, these estimates would be greatly affected.

For 2021, meanwhile, investment growth is cut to $8.1 \%$ (vs. $9.8 \%$ previously estimated) because the long electoral cycle that begins in October this year could slow down the recovery of the business confidence. Therefore, the 2020 National Plebiscite for the approval or rejection of the New Constitution may affect business expectations and increase the uncertainty of higher-income business sectors. Thus, growth in 2021 would remain at $4.4 \%$ (vs. 5.3\% previously estimated).

Regarding the external sector, the export and import projections for 2020 and 2021 remain. It should be noted that, although in August they maintained a stronger decline than in July, the behavior of these variables has remained in line with expectations, because both are on a path of gradual recovery in line with the progressive lack of focus at global, national and regional level.

When mentioning the above, the performance of the mining sector and especially copper extraction has not been significantly affected. Nevertheless, it must be considered, of course, that in the current world conditions, it is practically impossible to project with any degree of certainty the future global demand and supply of copper this year (Lagos, 2020). Department of Mining Engineering UC). In this sense, the Central Bank of Chile presents a panorama in the case of mining operations that continues to be uncertain in terms of investments that are not strictly necessary to maintain operations. In addition, the increase in contagion in some regions of the North Macrozone led to the temporary

Barra Novoa, R. (2021). Macro and microeconomic analysis of the impact of the COVID-19 pandemic in Chile and the projections of the central bank's. International Research Journal of Management, IT and Social Sciences, 8(3), 
stoppage of several works and in others, operational changes focused on cost control and reduction of sales prices have been implemented, further narrowing their margins of profit (Central Bank, 2020).

In short, a higher unemployment rate is expected for 2020 and 2021, mainly as a result of greater pressure that the inactive would exert on the labor market. This would not affect consumption significantly since there would be no major changes in the wage bill. Likewise, for 2021 a minor rebound in economic activity is expected because investment may be affected by the electoral cycle that begins in October this year (Grünwald \& García, 2020; De Graeve et al., 2008).

Table 1

Banco of Chile projections

\begin{tabular}{lccccc}
\hline Activity (a/a, \%) & 2019 & 2020 & - & 2021 & - \\
\hline GDP & 1,1 & $-5,2$ & - & 4,4 & 5,3 \\
Consumption & 0,8 & $-4,2$ & - & 4,5 & - \\
Investment & 4,4 & $-11,0$ & - & 8,1 & $(9,8)$ \\
Exports & $-2,3$ & 0,1 & - & 2,3 & - \\
Imports & $-2,3$ & $-12,5$ & - & 12,4 & \\
Unemployment (Dec.) & 7,1 & 15,0 & $(11,5)$ & 10,6 & $(8,5)$ \\
Inflation (Dec.) & 3,0 & 2,4 & $2,2)$ & 3,0 & - \\
TPM (Dec.\%) & 1,75 & 0,50 & - & 0,50 & - \\
CLP (Dec.) & 770 & 800 & - & 780 & - \\
\hline
\end{tabular}

Source: Elaboration based on Banchile Inversiones, 2020.

\section{Impact on the MSME Sector}

Through a survey carried out by the Eurochile Business Foundation, carried out among 128 companies of different sectors and sizes (micro, small and medium-sized companies), it shows that $73 \%$ of them state that they have lost more than half of their income. Of all the companies surveyed, $81 \%$ said that the crisis caused by COVID-19 has affected them significantly, paralyzing their business activities, while $12 \%$ say that the effect has been moderate. Only $7 \%$ of them indicate that the pandemic has affected them little.

The main pains of the business segment are further exacerbated by market failures and different institutional barriers that hamper business growth and survival. In this sense, the national diagnosis shows that micro and small companies continue to present various limitations that affect their industrial performance, including: i) limited access to financing; ii) fewer resources to invest in technology and human resources; iii) limited administrative and managerial capacities; iv) lower bargaining power with the market; v) difficulties in organizing scalable projects; vi) problems to expand its value offer in new markets; vii) difficulties in promoting value-creating industries and, viii) closure of contractor companies that are part of the supply chain of large national industries. These barriers hold back entrepreneurs when embarking on the creation of new businesses or cause established companies to operate with low economic profitability (Barra, 2019).

\section{Economic Growth Projections}

The International Monetary Fund (IMF) raised its GDP projection for Chile from $4.5 \%$ to $5.8 \%$ in 2021 . While for 2022, the organization foresees an expansion of the local economy of $3.5 \%$. Despite the news for the country, the organization warned that the Latin American and Caribbean region will not recover the level of its economic activity prior to the coronavirus pandemic until 2023, mainly due to the strong impact of the health crisis on employment.

\section{Results}

In an era in which economic and health crisis, global competition and technological changes are intensifying, companies must constantly seek to adapt, relearn, make their business structures more flexible and be able to withstand a series of adverse situations at the macro and microeconomic levels.

The quantitative information available indicates that horizontal inequalities are very large. The wage differences and the national unemployment rate between men and women have increased by $12.9 \%$. The labor market continues 
to be affected and the vast majority of workers in micro, small and medium-sized companies state that they have accepted the Employment Protection Law and have even used this measure for longer than expected. In the health field, health care has collapsed, especially in metropolitan, rural and peripheral areas, at the rate that the contagion and mortality rate of COVID-19 has not yet given up. In addition, the expectations of international outbreaks reported by who also condition the stability of the markets and further exacerbate the contexts of business insecurity.

The country's structural inequalities have developed at an unprecedented rate and with the associated distributional repercussions, inflation, unemployment and social confinement, disproportionately affecting lower-income households, losing many more economic incomes compared to the socio-economic segment. Economic "Upper Class" (IDB, 2020). The first estimates of the effects of COVID-19 indicate that government measures should protect employment, inject liquidity and achieve a series of tax reforms to neutralize the impacts of one of the largest recessions since the one registered in the early 1980s.

In this context, the Central Bank of Chile establishes that the Chilean economy will be affected in three central aspects: lower trade flows, deterioration in financial conditions and lower expectations of companies and individuals, affecting investment and consumption decisions. Proof of the above, will be the recovery of sales v/s recovery of staffing. In fact, it was assumed that the withdrawal of the Pension Funds would positively affect the behavior of the stock market and financial markets, but instead, this relationship has not occurred. Many of the official assumptions and projections are too catastrophic because they try to curb the fiscal deficit associated with increased social assistance. Finally, most of the industries that continue to face major downturns and pains are commerce, restaurants, hotels, tourism, artistic and cultural services, and transportation companies.

\section{Conclusion}

Official figures from the Ministry of Finance indicate that trend GDP is estimated at 1.8\%, $1.9 \%$ and $2.1 \%$ for the next few years, and according to the estimates of Klaus Schmidt-Hebbel "this certainly reflects a national disaster". The foregoing, he explains, that the global pandemic is imported, but the low figures of the trend GDP, has been a disaster where the culprits are the different institutional and economic agents of the country, pointing out that the numbers reflect the loss of growth that is seen in the country since the end of the 90's (Klaus Schmidt-Hebbel, 2020).

Considering the above, Chile needs to define, design and apply profound reforms to the functioning of the national economy and needs to recover the dynamism of the 90's, promote the productive transformation of the business segment and thereby correct the extreme inequality that still exists (French- Davis, 2018). In this context, French-Davis (2018) argues that sustained and inclusive growth is only viable if systematically significant space is introduced into the economic system for the productive development of the world of work and of SMEs. According to author, this requires fundamental corrections of the functioning of the economy and the influence and strengthening of regional and national institutions.

Behind these initiatives is the conviction that to guarantee a balanced and inclusive growth it is necessary to create a new productive reality, break down the structures to give a greater capacity to avoid the bankruptcy of companies, rediscover new business models, learn to relearn and adapt to new conditions of high commercial uncertainty through new innovation processes and collaborative spaces, in order to promote cooperation and accelerate new processes of digital and business transformation. Finally, the pains of social distancing in Chile have not been caused exclusively by the health crisis, but rather by social inequality and the unbalanced distribution of wealth that has been spreading for more than four decades in the country. Added to this is the low renewal of the entrepreneurial spirit of the cast of large companies, which played an important role in the different economic sectors of 1990s.

Considering that effectiveness of business incentives is a subject of debate among policy makers and researchers, the link established in the past and the entry of new companies, shape the new challenges on ways to make incentives more effective, to build a bridge between the co-creation of public policies and companies, in order to counteract market failures and promote more resilient economies during and after the pandemic.

Finally, with the argument of favoring entrepreneurship and injecting greater economic dynamism in times of crisis, Mariana Mazzucato (2019) in her book "The value of Things" suggests the importance of the contribution of the financial sector to increase their influence on the 'real' economy in the long run, deciding which activities are more important than others in setting a direction for the economy, stimulating tax credits for R\&D, subsidizing innovation, connecting and attracting entrepreneurs who create value and wealth, systematically invest in human capital and increase the capacity for public collaboration to gradually benefit the country's growth. Mazzucato suggests that "decisions about what constitutes value in national economies are made by combining different elements, among them;

Barra Novoa, R. (2021). Macro and microeconomic analysis of the impact of the COVID-19 pandemic in Chile and the projections of the central bank's. International Research Journal of Management, IT and Social Sciences, 8(3), 236-245. https://doi.org/10.21744/irjmis.v8n3.1471 
pragmatic policies, such as definitively adapting to technological change, as well as the need for economic and institutional actors, through a prolonged policy, to be able to deal with the inspiring area", creating a different path from the journey through the creation of new markets that they don't exist yet.

\section{Conflict of interest statement}

The author declared that he have no competing interests.

Statement of authorship

The author has a responsibility for the conception and design of the study. The author has approved the final article.

Acknowledgments

I am grateful to two anonymous reviewers for their valuable comments on the earlier version of this paper. 


\section{References}

Central Bank of Chile, Business Perceptions Report, August 2020. pp. 2-19, 2020.

De Graeve, F., Kick, T., \& Koetter, M. (2008). Monetary policy and financial (in) stability: An integrated micro-macro approach. Journal of Financial Stability, 4(3), 205-231. https://doi.org/10.1016/j.jfs.2007.09.003

Dutta, M. (2002). Asian Economic Community: intra-community macro-and-micro-economic parameters. Journal of Asian Economics, 13(4), 447-491. https://doi.org/10.1016/S1049-0078(02)00163-X

Fabeil, Noor Fzlinda, Pazim, Khairul Hanim, and Langgat, Juliana. (2020), The Impact of Covid-19 Pandemic Crisis on Micro-Enterprises: Entrepreneurs' Perspective on Business Continuity and Recovery Strategy. In: Journal of Economics and Business, Vol. 3, No.2, 837-844.

Fairlie, Robert. The Impact of COVID-19 on Small Business Owners: Evidence of Early-Stage Losses. From the Current Population Survey of April 2020.Stanford Institute for Economic Policy Research, University of California, Santa Cruz. pp. 1-2, 2020.

Ffrench-Davis, R. Economic Reforms in Chile (1973-2017), pp-14-563, 2018.

Gayle, AA, Smith, AW and Rocklov, J. (2020). The reproductive number of Covid-19 is higher compared to the SARS coronavirus, Journal of Travel Medicine, 27 (2).

Grünwald \& García, Banchile Inversiones., Department of Studies, Macroeconomic

Mazzucato., M. Book "The value of things, who produces and who wins in the global economy" First Edition, 2019.

Meluzín, T., \& Zinecker, M. (2014). Macro-and Microeconomic aspects of going Public in the Czech Republic and Poland. Procedia-Social and Behavioral Sciences, 156, 558-563. https://doi.org/10.1016/j.sbspro.2014.11.240

National Employment Survey (ENE), National Institute of Statistics (INE), 2020.

Rodrigo Ignacio Barra Novoa (2021). Economic impact of agricultural micro-enterprises in the Arica desert: an approach to business assistance provided by the Sercotec Arica Business Center of Chile. Journal of Contemporary Issues in Business and Government, 27(1), 2997-3018.

Rodrigo Ignacio Barra Novoa. (Volume. 6 Issue. 2, January - 2021) "Macro and Microeconomic View at the Impact of the Covid-19 Pandemic in Chile.", International Journal of Innovative Science and Research Technology (IJISRT), www.ijisrt.com. ISSN - 2456-2165, PP: - 333-338.

Scenario of September 2020. Grünwald \& García, Banchile Inversiones., Department of Studies, Unemployment Rate June-August 2020.

Schmidt - Hebbel Klaus., "With a trend GDP growth of $2 \%$ we are never going to be a developed country."

Tang, E., \& Peng, C. (2017). A macro-and microeconomic analysis of coal production in China. Resources Policy, 51, 234-242. https://doi.org/10.1016/j.resourpol.2017.01.007

Zore, Ž., Čuček, L., \& Kravanja, Z. (2016). Macro-and micro-economic perspectives regarding the syntheses of sustainable bio-fuels supply networks. In Computer Aided Chemical Engineering (Vol. 38, pp. 2253-2258). Elsevier. https://doi.org/10.1016/B978-0-444-63428-3.50380-5

Barra Novoa, R. (2021). Macro and microeconomic analysis of the impact of the COVID-19 pandemic in Chile and the projections of the central bank's. International Research Journal of Management, IT and Social Sciences, 8(3), 236-245. https://doi.org/10.21744/irjmis.v8n3.1471 